\title{
DESIGNATION OF INTEGRATED PERCEPTIBLEWATER VAPOUR FOR LOCAL RURAL REGION USING GPS SATELLITE TECHNIQUE
}

\author{
Malgorzata Kirschenstein $^{1}$, Kamil Krasuski ${ }^{1,2}$, Janusz Cwiklak ${ }^{1}$ \\ ${ }^{1}$ Polish Air Force Academy, Poland; ${ }^{2}$ District Office in Ryki, Poland \\ kk_deblin@wp.pl, j.cwiklak@wsosp.pl
}

\begin{abstract}
The Integrated Precipitable Water Vapour (IPWV) parameter is applied to the description of atmospheric changes in the area of climatology, meteorology and geophysics. This paper presents research results concerning the determination of the IPWV parameter, using GPS satellite technique. The IPWV term was designated on the basis of values of the Zenith Wet Delay (ZWD) product. The ZWD parameter was estimated using undifference GPS code and phase observations in the Precise Point Positioning (PPP) method. The computations were conducted in the magicPPP and APPS software packages for GPS observations from the REF1 reference station. The REF1 reference station was installed at the military aerodrome in the town of Dęblin, in Ryki rural region, in Lublin V of south-eastern Poland. The paper presents and compares the results of the IPWV parameter from the magicPPP and APPS software packages. In addition, the IPWV parameter is estimated by means of an empirical troposphere model of the RTCA-MOPS solution. The mean difference of the IPWV term between the APPS and the magicPPP solution equals $3.6 \mathrm{~mm}$, with the RMS bias of approximately $0.4 \mathrm{~mm}$. Moreover, the mean difference of the IPWV parameter between the APPS and RTCA-MOPS solution amounts to $5.7 \mathrm{~mm}$, with the RMS bias nearing $0.2 \mathrm{~mm}$. In addition, the mean difference of the IPWV term between the magic PPP and RTCA-MOPS solution is approximately $2.1 \mathrm{~mm}$, with the RMS bias being close to $0.6 \mathrm{~mm}$.
\end{abstract}

Keywords: IPWV, GPS, ZWD, reference station, linear regression.

\section{Introduction}

One of the basic products of the tropospheric delay in satellite GPS technology is the parameter determining the content of condensed water vapour in the vertical direction of the atmosphere (Precipitable Integrated Water Vapour) [1]. The parameter of condensed water vapour can be very easily obtained using the information with regard to the tropospheric delay value. The total tropospheric delay is determined on the basis of the sum of components of the hydrostatic and wet parts. In order to determine the content of condensed water vapour, the wet part parameter of the tropospheric delay, the so-called ZWD parameter (Zenith Wet Delay) [2], is used.

The determination of the IPWV parameter of the condensed water vapour is significant for the monitoring of tropospheric state change in the local area, for example, in the countryside or in poorly urbanized area. In the analysis of the change in the value of the IPWV parameter, two basic factors are taken into account: the meteorological and the climatological one. In the meteorological aspect, the change in the IPWV parameter is determined as a function of the air temperature, atmospheric pressure and air humidity. In the climatological aspect, the change in the IPWV parameter is determined in the function of seasonal resolution as well as of spatial resolution. Spatial resolution is defined by means of the geographical latitude of the observation site, whereas the seasonal resolution is expressed by the season of the year [3].

It should be emphasized that the IPWV parameter monitoring for large rural areas or poorly urbanized town areas is one of the elements of examining the state of the atmosphere. Unfortunately, monitoring the IPWV parameter changes is connected with the construction of a special technical infrastructure, namely the GNSS reference station along with a satellite antenna-receiver system. The GNSS satellite receiver is mainly responsible for processing, collecting, cataloguing and archiving GNSS observations. Additionally, each GNSS reference station must be equipped with control software in order to perform nearly real-time and post-processing calculations. It needs to be stressed that the control software for the GNSS reference station, apart from its purely geodetic application, i.e. the determination of coordinates, should also include geophysical modules for the purpose of studying the state of the atmosphere $[4,5]$. The continuous assessment of the IPWV parameter value will allow determining the trend of changes of this parameter over a specific area. In addition, long-term tests of the IPWV parameter will show the relationships of this parameter against the background of meteorological and climatological factors. Monitoring the changes in the IPWV parameter will also allow developing a system of alerting communities in the event of dangerous and violent weather 
phenomena in rural areas. Another component of the conducted research is the possibility to develop a system counteracting the effects of dangerous weather phenomena in the countryside.

The main purpose of this work is to present the results of the IPWV (Integrated Precipitable Water Vapour) parameter determination for the area of the town of Dęblin, which is located in sparsely populated areas, mostly covered with forest and arable fields. The IPWV parameter was determined using the ZWD (Zenith Wet Delay) value, whereas the ZWD parameter was determined for the reference station REF1 in Dęblin, on the basis of calculations in APPS and magicPPP software packages. In addition, the RTCA-MOPS tropospheric empathic model was used in the calculations.

\section{Materials and methods}

The Integrated Water Vapour (IWV) parameter is closely associated with the Zenith Wet Delay in GPS satellite measurements. The functional dependency between ZWD and IWV can be obtained as below [6]:

$$
I W V=k \cdot Z W D,
$$

where $I W V-$ Integrated Water Vapour, $\mathrm{kg} \cdot \mathrm{m}^{-2}$;

$Z W D$ - Zenith Wet Delay, m;

$k$ - constant value, dimensionless.

The coefficient $k$ can be expressed in equation (1) as follows:

$$
1 / k=10^{-6} \cdot\left(C_{3} / T m+C_{2}\right) \cdot R w,
$$

where $C_{3}=3.75 \cdot 10^{5}$, empirical constant, $\mathrm{K}^{2} \cdot(\mathrm{hPa})^{-1}$;

$C_{2}=24$, empirical constant, $\mathrm{K} \cdot(\mathrm{hPa})^{-1}$;

$R w=461.525$, gas constant, $\mathrm{J} \cdot(\mathrm{K} \cdot \mathrm{kg})^{-1}$;

$\mathrm{Tm}$ - mean temperature of water vapour, $\mathrm{K}$;

$T m=70.2 \pm 0.72 \cdot T_{0}$

$T_{0}$ - surface temperature.

The appointed IWV value enables the determination of the Integrated Precipitable Water Vapour (IPWV) parameter, as follows:

$$
I P W V=I W V / \rho,
$$

where $I P W V$ - Integrated Precipitable Water Vapour, mm;

$\rho=998$, water density, $\mathrm{kg} \cdot \mathrm{m}^{-3}$.

It is necessary to mention that the IWV parameter is expressed in $\mathrm{kg} \cdot \mathrm{m}^{-3}$, while IPWV is given in millimetres, respectively.

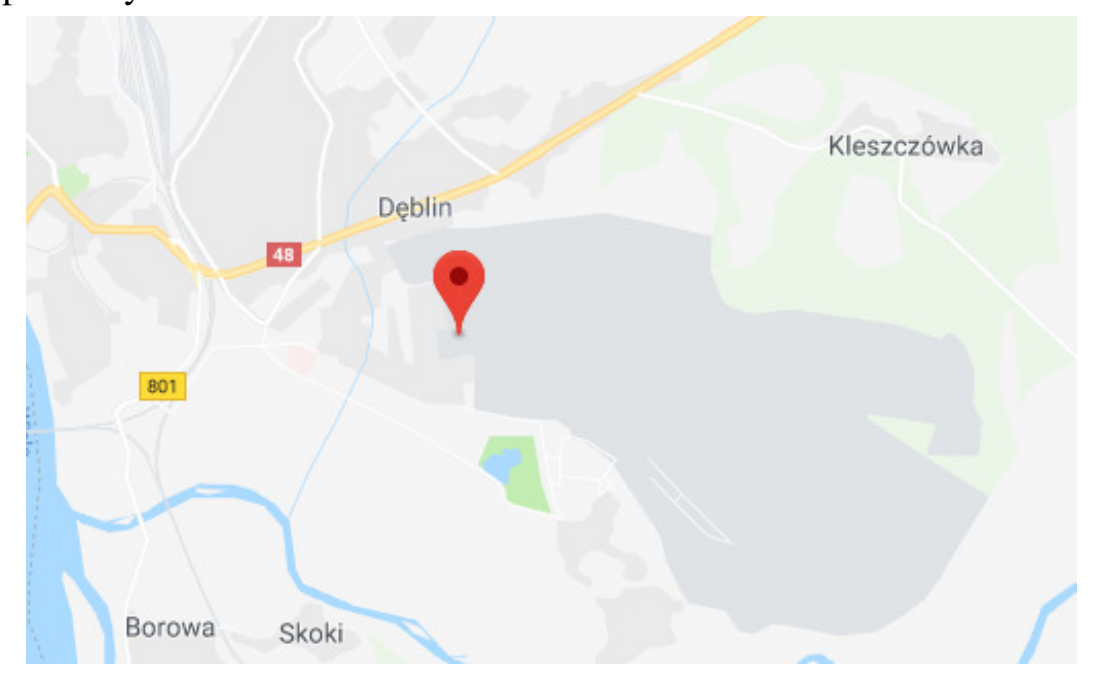

Fig. 1. Localization of REF1 reference station in town of Dęblin [7]

In the research experiment, the IPWV parameter was determined for the reference station REF1 located in Dęblin, a town is situated in Lublin Voivodship in the south-eastern part of Poland (Fig. 1). 
The technical infrastructure of the REF1 reference station was located on the roof of the Aeronautics Faculty of the Air Force Academy in Dęblin. The REF1 reference station was used for air experiments for the sake of implementation of GNSS satellite technique in air navigation [8]. In addition, the REF1 reference station made it possible to monitor the state of the ionosphere and troposphere for the needs of continuous development of GNSS observations. The REF1 reference station in Dęblin is equipped with a "choke-ring" antenna, which is resistant to the effect of multiple GNSS signals. The station is also equipped with the Topcon HiperPro two-frequency receiver. The technical infrastructure of the REF1 station ensured constant work in the post-processing mode and in the RTK mode as the base station for the mobile receiver. The Topcon Geodesy Surveillance Receiver allowed tracking of the constellations of GPS and GLONASS satellites.

The code-phase GPS observations, which were recorded and stored in the Topcon HiperPro receiver memory card, could be used to determine the IPWV parameter, in accordance with the mathematical relationships (see equations 1-3). The IPWV parameter was determined on the basis of the ZWD values from magicPPP and APPS programmes. The IPWV parameter calculation was made for GPS observations on June 1, 2010, from 09:40:30 hours up to 10:36:30 hours, according to GPST (GPS Time). In the first place, the ZWD parameter was determined using the PPP (Precise Point Positioning) method for GPS difference observations in magicPPP [9] and APPS [10]. Typically, the ZWD parameter is modelled using random walk in a stochastic process in the PPP method [11]. The ZWD parameter is solved using Kalman filtration or the least squares method in a sequential process. The interval of determining the ZWD parameter in the magicPPP programme equals 30 seconds, whereas the computation step in the APPS programme is also set at 30 seconds. The values of ZWD parameters in the magicPPP and APPS programmes are saved to a text file, which is a part of the final report of the performed calculations. The magicPPP programme also allows specifying other tropospheric products in the form of ZHD (Zenith Hydrostatic Delay) and ZTD (Zenith Total Delay) parameters. In the APPS programme, the ZHD, ZTD parameters as well as the horizontal gradients of the tropospheric delay $G_{N}$ and $G_{E}$ are determined. The RTCA-MOPS tropospheric model [12] was also used for the needs of the research, for which the values of the ZWD and IPWV troposphere parameters were also determined.

\section{Results and discussion}

Figure 2 demonstrates the determined values of ZWD parameters from the magicPPP and APPS programmes and additionally of the empirical RTCA-MOPS model.

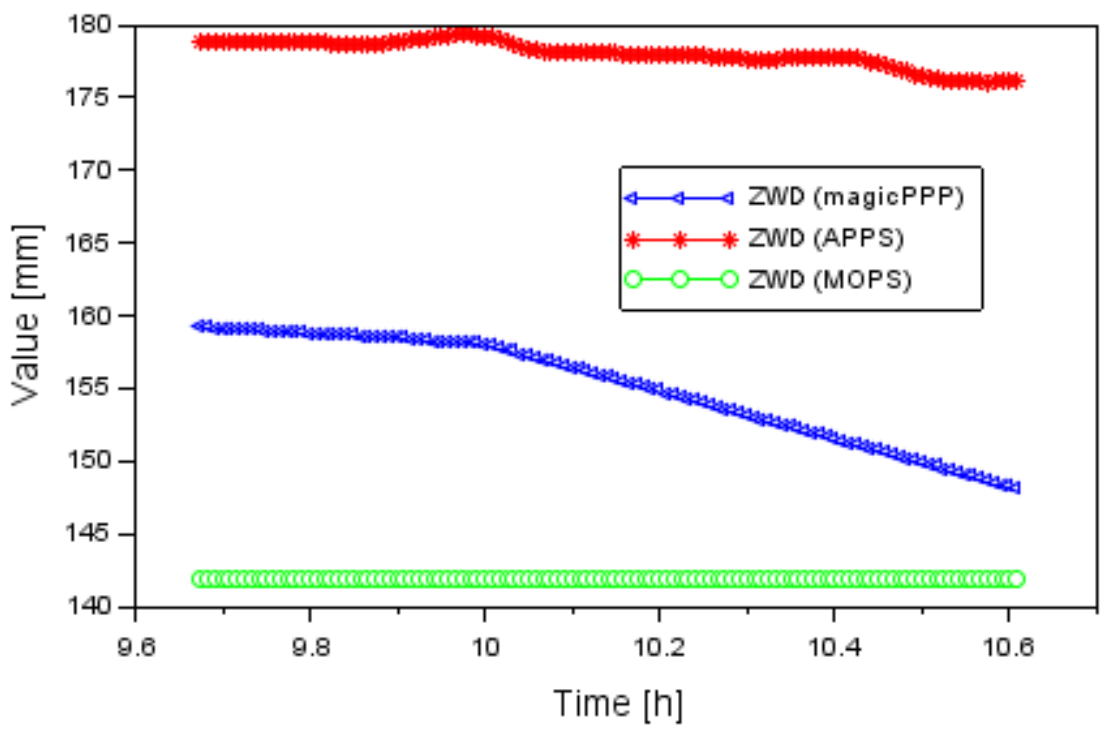

Fig. 2. Results of ZWD parameter

The average value of the ZWD parameter from the magicPPP programme is $155.1 \mathrm{~mm}$, with the range of findings from $148.2 \mathrm{~mm}$ to $159.3 \mathrm{~mm}$. Moreover, the median parameter for ZWD in the magicPPP programme equals $155.8 \mathrm{~mm}$. Starting with 10:00 in accordance with GPST, it is evident 
that the ZWD values from the magicPPP programme are being systematically reduced. The average value of ZWD from the APPS programme is $178.1 \mathrm{~mm}$, with a dispersion of the obtained results from $176.1 \mathrm{~mm}$ to $179.4 \mathrm{~mm}$. The median parameter for ZWD from the APPS programme is equal to 178.1 $\mathrm{mm}$. When comparing the ZWD values from magicPPP and APPS programmes, it is worth noting that the dispersion of the ZWD parameter is greater in the magicPPP programme, rather than in the APPS one. The ZWD value from the empirical RTCA-MOPS tropospheric model is constant and amounts to $141.9 \mathrm{~mm}$.

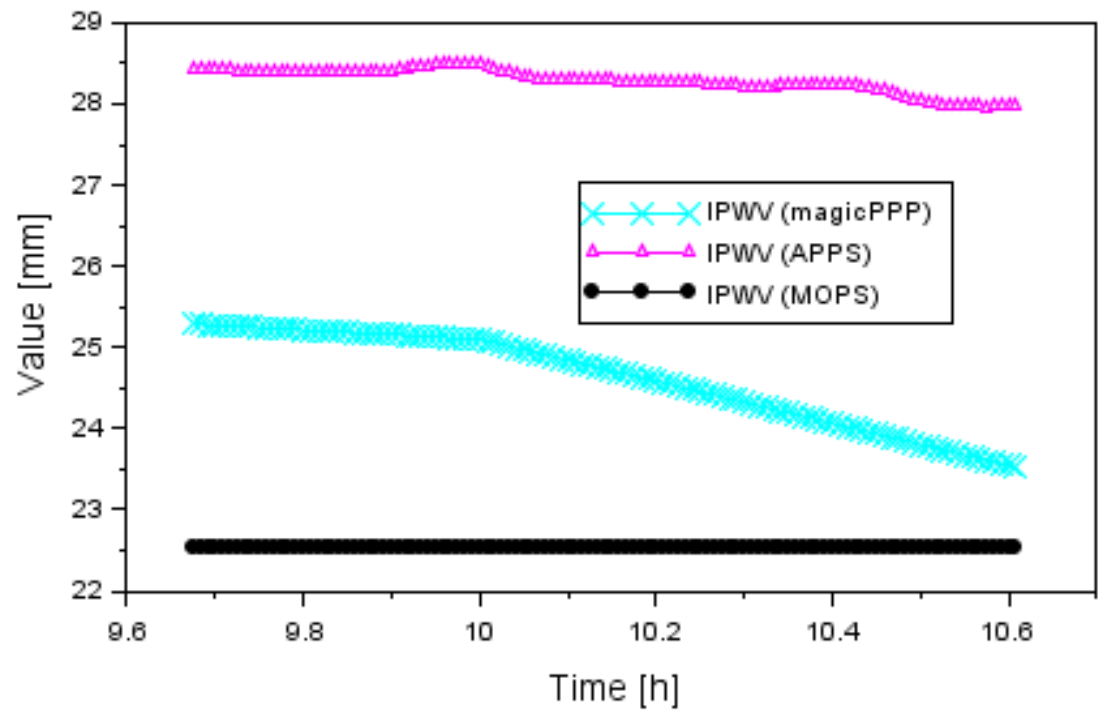

Fig. 3. Results of IPWV parameter

Figure 3 presents the determined values of IPWV parameters from the magicPPP and APPS programmes and additionally of the RTCA-MOPS empirical model. The average value of the IPWV parameter from the magicPPP programme equals $24.6 \mathrm{~mm}$, with the range of the obtained findings between $23.5 \mathrm{~mm}$ and $25.3 \mathrm{~mm}$. Moreover, the median parameter for the IPWV findings in the magicPPP programme is $24.7 \mathrm{~mm}$. The average value of the IPWV parameter from the APPS programme is $28.3 \mathrm{~mm}$, with the range of the obtained findings between $27.9 \mathrm{~mm}$ and $28.5 \mathrm{~mm}$. Furthermore, the median parameter for the IPWV results in the APPS programme is equal to $28.3 \mathrm{~mm}$. The value of the IPWV parameter from the RTCA-MOPS tropospheric empirical model is constant and equal to $22.5 \mathrm{~mm}$.

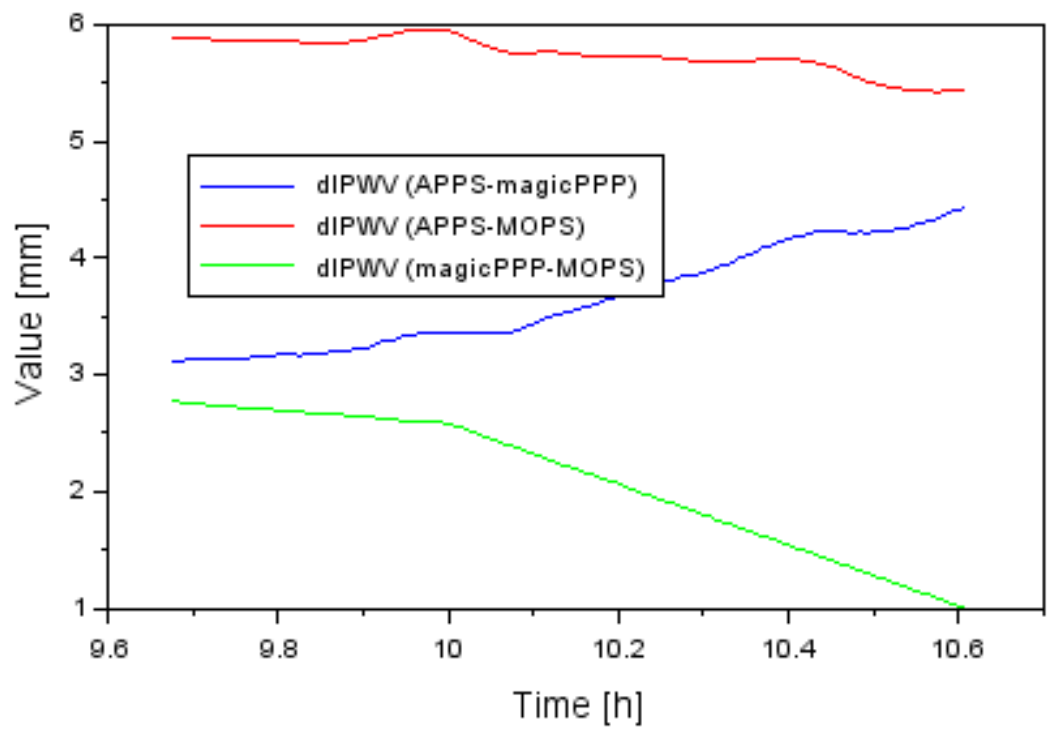

Fig. 4. Difference of results of IPWV parameter 
Figure 4 presents differences in the values of the determined IPWV parameters from the magicPPP and APPS programmes and additionally of the RTCA-MOPS empirical model. The IPWV parameter difference values were determined on the basis of the following dependence:

$$
\begin{gathered}
d I P W V=I P W V_{A P P S}-I P W V_{\text {magic } P P P}, \\
d I P W V=I P W V_{A P P S} I P W V_{M O P S}, \\
d I P W V=I P W V_{\text {magic } P P P}-I P W V_{M O P S},
\end{gathered}
$$

where $d I P W V$ - difference of the IPWV parameter, mm;

$I P W V_{A P P S}-I P W V$ values from the APPS software, $\mathrm{mm}$;

$I P W V_{\text {magic } P P P}-$ IPWV values from magicPPP software, $\mathrm{mm}$;

$I P W V_{M O P S}-$ IPWV values from the RTCA-MOPS model, $\mathrm{mm}$.

The average value of $d I P W V$ parameter between the APPS solution and magicPPP is $3.6 \mathrm{~mm}$, with the RMS error of $0.4 \mathrm{~mm}$. The range of results of $d I P W V$ parameter between the APPS solution and magicPPP ranges from $3.1 \mathrm{~mm}$ to $4.4 \mathrm{~mm}$. In addition, the median of $d I P W V$ parameter between the APPS solution and magicPPP is equal to $3.5 \mathrm{~mm}$. The average value of $d I P W V$ parameter between the APPS and RTCA-MOPS solution is $5.7 \mathrm{~mm}$, with the RMS error of $0.2 \mathrm{~mm}$. The magnitude of the obtained values of $d I P W V$ parameter between the APPS and RTCA-MOPS solution ranges from 5.4 $\mathrm{mm}$ to almost $6 \mathrm{~mm}$. Besides, the median of $d I P W V$ parameter between the APPS and RTCA-MOPS solution is equal to $5.8 \mathrm{~mm}$. The average value of $d I P W V$ parameter between the magicPPP and RTCA-MOPS solution is $2.1 \mathrm{~mm}$, with the RMS error of approximately $0.6 \mathrm{~mm}$. The range of results of $d I P W V$ parameter between the magicPPP and RTCA-MOPS solutions is between $1 \mathrm{~mm}$ and 2.8 $\mathrm{mm}$. In addition, the median of $d I P W V$ parameter between the magicPPP and RTCA-MOPS solution is equal to $2.2 \mathrm{~mm}$.

Figures 5, 6 and 7 present the characteristics of changes in the $d I P W V$ parameter by means of the linear regression function [13], as below:

$$
d I P W V=a \cdot T+b
$$

where $a$-coefficient of linear regression, $\mathrm{mm} \cdot$ hour $^{-1}$;

$b$ - coefficient of linear regression, $\mathrm{mm}$;

$T$ - measurement time, hour.

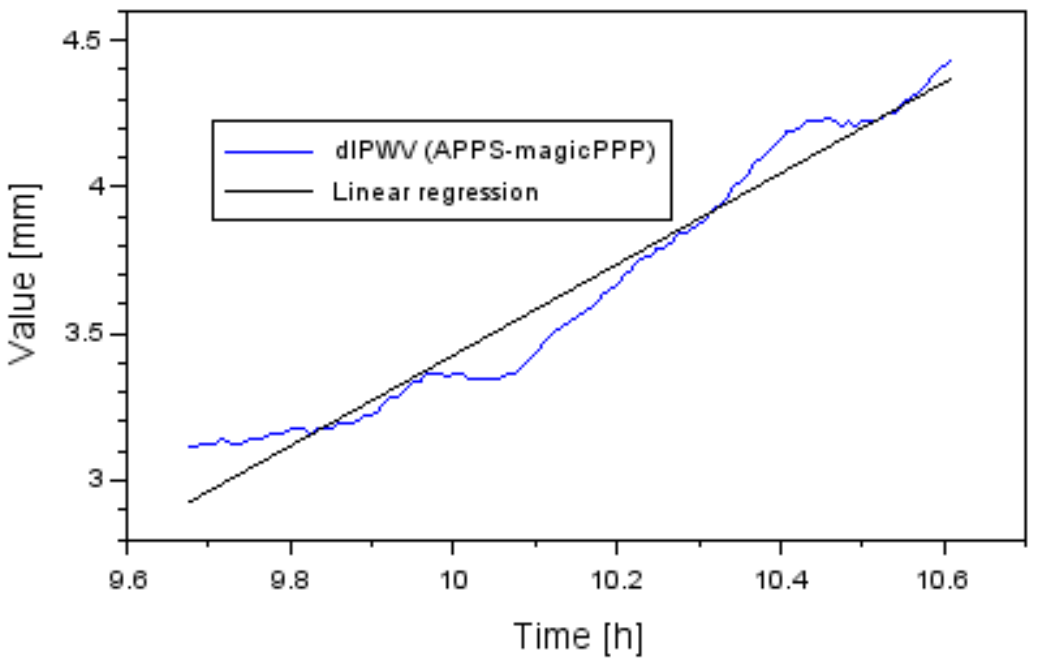

Fig. 5. Linear regression of IPWV parameter based on APPS and magicPPP solution

The parameter values $(a, b)$ for $d I P W V$ parameters were determined using the least squares method in a sequential process. The linear regression function is the basic mathematical formula used to describe the change in the $d I P W V$ parameter in relation to the measurement time. Figure 5 shows the linear regression function against the background of the $d I P W V$ parameter change obtained from comparing IPWV results between the APPS solution and magicPPP. The parameter value $(a, b)$ for $d I P W V$ parameters obtained from the APPS solution and magicPPP is respectively: parameter 
$a=1.55 \mathrm{~mm} \cdot$ hour $^{-1}$, and parameter $b=-12.03 \mathrm{~mm}$. The standard deviation of the linear regression fit in relation to $d I P W V$ value is $0.09 \mathrm{~mm}$. The dispersion of the obtained $d I P W V$ values for the linear regression function ranges from $2.9 \mathrm{~m}$ to $4.4 \mathrm{~mm}$. The linear regression function has a positive trend, as evidenced by the value of the linear coefficient $a$.

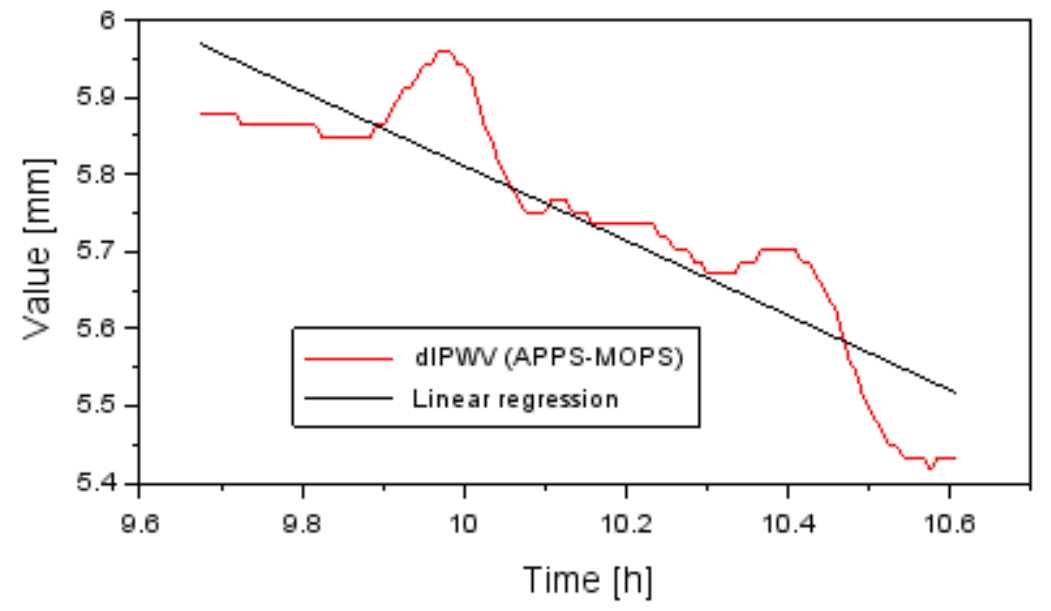

Fig. 6. Linear regression of IPWV parameter based on APPS and RTCA-MOPS solution

Figure 6 shows the linear regression function against the background of the change in the $d I P W V$ parameter obtained from the comparison of IPWV results between the APPS solution and RTCAMOPS. The parameter value $(\mathrm{a}, \mathrm{b})$ for $d I P W V$ parameters obtained from the APPS and RTCA-MOPS solution is respectively: parameter $a=-0.48 \mathrm{~mm} \cdot$ hour $^{-1}$, whereas parameter $b=10.66 \mathrm{~mm}$. The standard deviation of the linear regression fit in relation to $d I P W V$ value is $0.07 \mathrm{~mm}$. The dispersion of $d I P W V$ values obtained for the linear regression function is from $5.5 \mathrm{~m}$ to almost $6 \mathrm{~mm}$. The linear regression function has a negative trend, as evidenced by the value of the linear coefficient $a$.

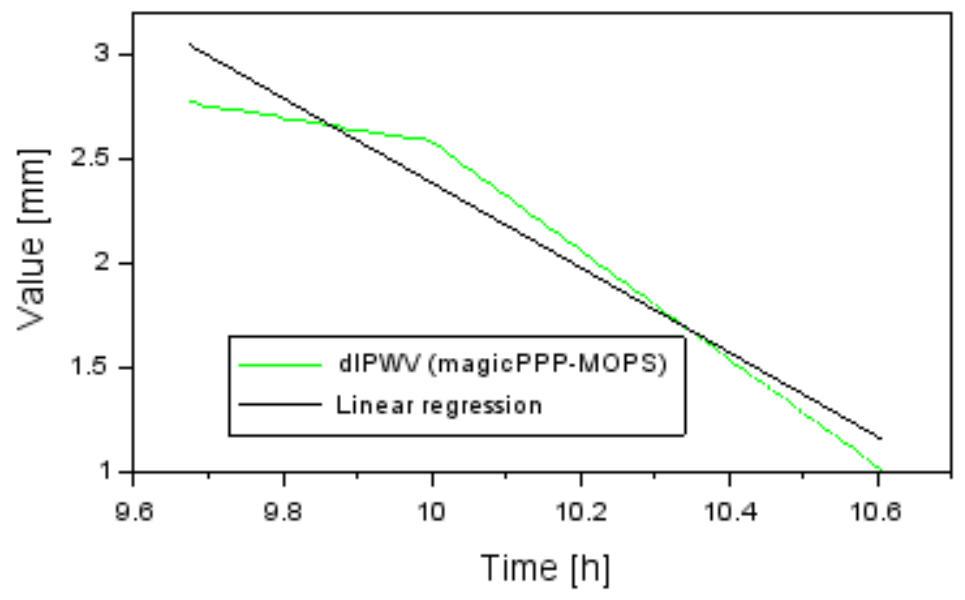

Fig.7. Linear regression of IPWV parameter based on magicPPP and RTCA-MOPS solution

In order to assess the changes in time, the linear regression function was used against the background of the $d I P W V$ parameter change (Fig. 7). The $d I P W V$ parameter was obtained from the comparison of IPWV results between the magicPPP and RTCA-MOPS solutions. The parameter value $(a, b)$ for $d I P W V$ parameters obtained from the magicPPP and RTCA-MOPS solution is respectively: parameter $a=-2.03 \mathrm{~mm} \cdot$ hour $^{-1}$, and parameter $b=22.69 \mathrm{~mm}$. The standard deviation of the linear regression fit in relation to $d I P W V$ value is $0.12 \mathrm{~mm}$. The dispersion of the obtained $d I P W V$ values for the linear regression function is from $1.1 \mathrm{~m}$ to over $3 \mathrm{~mm}$. The linear regression function has a negative trend, as evidenced by the value of the linear coefficient $a$.

Table 1 presents statistical parameters for the linear regression function describing changes in the $d I P W V$ value with the elapse of the measurement time. The linear regression coefficients determined are expressed in units: linear coefficient $a\left(\mathrm{~mm} \cdot\right.$ hour $\left.^{-1}\right)$, whereas the linear coefficient $b(\mathrm{~mm})$. The 
character of the linear coefficient $a$ is positive for the $d I P W V$ parameter (APPS-magicPPP), and negative for the $d I P W V$ (APPS-MOPS) and $d I P W V$ (magicPPP-MOPS) parameters. The character of the linear coefficient $b$ is negative for the $d I P W V$ parameter (APPS-magicPPP), and positive for the $d I P W V$ (APPS-MOPS) and $d I P W V$ (magicPPP-MOPS) parameters. In addition, the standard deviation of the linear regression fit in relation to the actual $d I P W V$ values is the smallest for $d I P W V$ solution (APPS-MOPS), and accordingly the largest for $d I P W V$ solution (magicPPP-MOPS). It follows that the smallest value of the standard deviation is $\pm 0.07 \mathrm{~mm}$, and the largest $\pm 0.12 \mathrm{~mm}$ respectively. In addition, the smallest patch spread is for the $d I P W V$ parameter (APPS-MOPS), and the largest for the $d I P W V$ parameter (magicPPP-MOPS), respectively.

Table 1

Statistical value of the dIPWV parameter

\begin{tabular}{|c|c|c|c|}
\hline $\begin{array}{c}\text { Statistical } \\
\text { parameters }\end{array}$ & $\begin{array}{c}\boldsymbol{d I P W V} \\
\text { (APPS-magicPPP) }\end{array}$ & $\begin{array}{c}\boldsymbol{d I P W V} \\
\text { (APPS-MOPS) }\end{array}$ & $\begin{array}{c}\boldsymbol{d I P W V} \\
\text { (magicPPP-MOPS) }^{-1}\end{array}$ \\
\hline $\begin{array}{c}\text { Estimated } \\
\text { parameters }\end{array}$ & $\begin{array}{c}a=1.55 \mathrm{~mm} \cdot \text { hour }^{-1} \\
b=-12.03 \mathrm{~mm}\end{array}$ & $\begin{array}{c}a=-0.48 \mathrm{~mm} \cdot \text { hour }^{-1} \\
b=10.66 \mathrm{~mm}\end{array}$ & $\begin{array}{c}a=-2.03 \mathrm{~mm} \cdot \text { hour }^{-1} \\
b=22.69 \mathrm{~mm}\end{array}$ \\
\hline Range of values & $2.9 \mathrm{~mm} \div 4.4 \mathrm{~mm}$ & $5.5 \mathrm{~mm} \div 6 \mathrm{~mm}$ & $1.1 \mathrm{~mm} \div 3 \mathrm{~mm}$ \\
\hline Range of residuals & $-0.2 \mathrm{~mm} \div 0.2 \mathrm{~mm}$ & $-0.1 \mathrm{~mm} \div 0.1 \mathrm{~mm}$ & $-0.2 \mathrm{~mm} \div 0.3 \mathrm{~mm}$ \\
\hline Standard deviation & $\pm 0.09 \mathrm{~mm}$ & $\pm 0.07 \mathrm{~mm}$ & $\pm 0.12 \mathrm{~mm}$ \\
\hline
\end{tabular}

The research results presented in the paper concerned the determination of the content of IPWV condensed water vapour using the GPS satellite technique. It should be emphasized that the scientific research was conducted for the REF1 reference station, located at middle geographical latitudes in central Europe. It should be stressed that the values of the IPWV parameter for GNSS reference stations located on the equator or near the polar circle may be utterly different. For the area of Ryki region, the REF1 reference station is a crucial element for the technical infrastructure of the atmosphere monitoring system. It is worth noting, at this point, that in the town of Dęblin there is also a technical infrastructure of meteorological sensors, such as: SYNOP, METAR or TAF. The combination of GNSS tropospheric products from the REF1 reference station, meteorological data from the SYNOP Dęblin/Irena station or meteorological products from METAR (or TAF) report enables a full development of an integrated atmosphere monitoring system for the region of Ryki. In the future, the authors of this article plan to launch scientific research focused on the integrated atmosphere monitoring system for the region of Ryki.

\section{Conclusions}

The article presents the values of the Integrated Precipitable Water Vapour (IPWV) parameter, based on GPS satellite measurements. The values of the IPWV parameter were determined on the basis of the tropospheric Zenith Wet Delay (ZWD) parameter. The ZWD parameter was determined in the PPP method with the use of the GPS observation in magicPPP and APPS software. The numerical calculations were performed for daily GPS observation from the referential REF1 station on 1 June 2010. On the basis of the results achieved in the course of calculations, it is established that the average value of IPWV from the magicPPP software equals $24.6 \mathrm{~mm}$, whereas from the APPS software it equals $28.3 \mathrm{~mm}$. Moreover, the difference of the IPWV parameter based on the magicPPP and APPS solution equals $3.6 \mathrm{~mm}$, with the RMS error equal to $0.4 \mathrm{~mm}$. In addition, the IPWV parameter was estimated by means of an empirical troposphere model of the RTCA-MOPS solution. The average value of IPWV term is approximately $22.5 \mathrm{~mm}$ based on the RTCA-MOPS model. In addition, the average difference of the IPWV parameter between the APPS and RTCA-MOPS solution amounts to $5.7 \mathrm{~mm}$, with the RMS bias close to $0.2 \mathrm{~mm}$. Furthermore, the average difference of the IPWV term between the magicPPP and RTCA-MOPS solution is approximately $2.1 \mathrm{~mm}$ and of the RMS - approximately $0.6 \mathrm{~mm}$. 


\section{References}

[1] Igondová M., Cibulka D. Precipitable Water Vapour and Zenith Total Delay time series and models over Slovakia and vicinity, Contributions to Geophysics and Geodesy, Vol. 40/4, 2010, pp. 299-312.

[2] Kleijer F. Troposphere modeling and filtering for precise GPS leveling, Ph. D. thesis, Delft University of Technology, ISBN 90-6132-284-7, 2004.

[3] Kruczyk M. GNSS tropospheric delay and its use in research on state of atmosphere, „Prace Naukowe Geodezja", z. 54, ISBN 978-83-7814-151-8, 2013. (In Polish)

[4] Graszka W., Oruba A., Ryczywolski M., Wajda S. Poradnik użytkownika systemu ASG-EUPOS, Wydanie 3, poprawione i uzupełnione, GUGIK, Warszawa 2013. (In Polish)

[5] Krasuski K. Utilization AUSPOS service for determination of reference station coordinates, Zeszyty Naukowe, vol. 30, nr. 3, 2016, pp. 145-154. (In Polish)

[6] Bosy J. Precise processing of satellite GPS observations in local networks located in mountain areas, Wydawnictwo Akademii Rolniczej we Wrocławiu, Nr 522, ISSN 0867-7964, 2005. (In Polish)

[7] Figure 1. [online] [01.01.2018]. Available at: https://www.google.pl/maps/place/51 \%C2 \%B033'20.0\%22N+21\%C2\%B052'08.7\%22E/@ 51 $.5540533,21.8398706,12.95 \mathrm{z} / \mathrm{data}=! 4 \mathrm{~m} 5 ! 3 \mathrm{~m} 4 ! 1 \mathrm{~s} 0 \times 0: 0 \times 0 ! 8 \mathrm{~m} 2 ! 3 \mathrm{~d} 51.555545 ! 4 \mathrm{~d} 21.86909 ? \mathrm{hl}=\mathrm{pl}$

[8] Ćwiklak J., Jafernik H. The monitoring system for aircraft and vehicles of public order services based on GNSS, Annual of Navigation, no. 16, 2010, 15-24.

[9] URL1. [online] [01.01.2018]. Available at: magicgnss.gmv.com/ppp.

[10] URL2. [online] [01.01.2018]. Available at: http://apps.gdgps.net/apps_file_upload.php.

[11]Leandro R., Santos M., Langley R. Analyzing GNSS data in precise point positioning software, GPS Solutions, vol. 15, Issue 1, pp. 1-13, DOI 10.1007/s10291-010-0173-9, 2011.

[12] Sanz Subirana J., Juan Zornoza J. M., Hernández-Pajares M. GNSS Data Processing, Volume I: Fundamentals and Algorithms, Publisher: ESA Communications, ESTEC, Noordwijk, Netherlands, ISBN 978-92-9221-886-7, 2013.

[13] Kruczyk M., Mazur A. Tropospheric Delay (ZTD) and Precipitable Water data from COSMO model vs. geodetic GPS network data, 5 Working Group on Verification and Case Studies, COSMO Newsletter No. 13: April 2013, pp. 69-82. 